
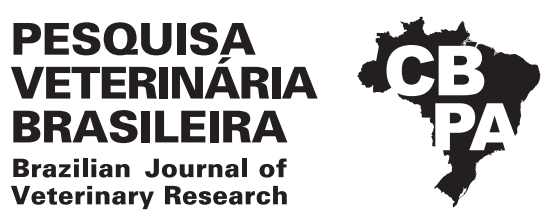

Pesq. Vet. Bras. 38(9):1808-1817, setembro 2018 DOI: 10.1590/1678-5150-PVB-5150

Artigo Original

ISSN 0100-736X (Print)

ISSN 1678-5150 (Online)

\title{
Mastocitoma cutâneo canino: estudo retrospectivo dos casos atendidos pelo Serviço de Oncologia do Hospital Veterinário da FCAV-Unesp, Campus Jaboticabal, de 2005 a $2015^{1}$
}

\author{
Ana Carolina F. Souza ${ }^{2 *}$, Ana Lucia Pascoli ${ }^{3}$, Marilia G.P.A. Ferreira ${ }^{4}$, \\ Nazilton P. Reis Filho ${ }^{5}$, Izabel C.R. Silva ${ }^{6}$, Rogério R. Santos ${ }^{7}$, André M. Faro ${ }^{8}$ \\ e Andrigo B. De Nardi ${ }^{9}$
}

\begin{abstract}
Souza A.C.F., Pascoli A.L., Ferreira M.G.P.A., Reis Filho N.P., Silva I.C.R., Santos R.R., Faro A.M. \& De Nardi A.B. 2018. [Canine cutaneous mast cell tumors: retrospective study of cases attended by the oncology service at the Veterinary Hospital of FCAV-Unesp, Jaboticabal, from 2005 to 2015.] Mastocitoma cutâneo canino: estudo retrospectivo dos casos atendidos pelo serviço de oncologia do Hospital Veterinário da FCAV-Unesp, Campus Jaboticabal, de 2005 a 2015. Pesquisa Veterinária Brasileira 38(9):1808-1817. Departamento de Clínica e Cirurgia Veterinária, Universidade Estadual Paulista, Campus Jaboticabal, Via de acesso Prof. Paulo Donato Castelane, Jaboticabal, SP 14884-900, Brazil. E-mail: anacarolina@ciave.com.br

This study analyzed the cases of cutaneous mastocytomas in dogs seen at the Governador Laudo Natel Veterinary Hospital of the College of Agrarian and Veterinary Sciences (FCAV), Unesp, in Jaboticabal, from 2005 to 2015. The objective was to determine the occurrence of this neoplasm regarding breed, sex, and age, the most affected body parts and observed neoplastic characteristics; the most widely used diagnosis methods, the main histological grades and recommended treatments, to evaluate size changes in relation to lymph nodes, recurrence rate, metastasis and to verify possible associations between the evaluated variables. The clinical files of 192 patients were evaluated. The most affected dogs were of mixed breed $(n=46,23.96 \%)$, followed by Boxer $(n=40,20.83 \%)$ and Pitbull $(n=27,14.06 \%)$. Most of the dogs were females $(n=107,55.7 \%)$, aged between 7 and 11 years old $(n=120,62.5 \%)$. Thirtytwo patients had $(16.7 \%)$ tumors located in the pelvic limb, followed by thoracic limbs $(10.4 \%$ $\mathrm{n}=20$ ). Sixty-five animals had ulcerated nodules (33.9\%), of which 96 had firm consistency $(50 \%)$. Seventy-six animals had multiple nodules $(39.6 \%)$, and $39.1 \%$ of the sample $(n=75)$ had nodules larger than three centimeters. The most used diagnosis method was fine needle aspiration together with histopathology (HT), totaling $39.8 \%$ of nodules $(\mathrm{n}=66)$, followed by HT in $37.3 \%$ of the patients $(n=62)$. Regarding the histological variables, 18 patients had grade I (11.8\%), 112 grade II $(73.7 \%)$, and 22 grade III (14.5\%) classified according to Patnaik et al. (1984). According to the classification of Kiupel et al. (2011), 37 cases were classified as high grade (35.2\%) and 68 as low grade (64.8\%). Statistical association was observed when the presence of solitary/multiple nodules and the histological grade were
\end{abstract}

\footnotetext{
${ }^{1}$ Recebido em 4 de novembro de 2017.

Aceito para publicação em 17 de novembro de 2017.

${ }^{2}$ Departamento de Clínica e Cirurgia Veterinária, Faculdade de Ciências Agrárias e Veterinárias (FCAV), Universidade Estadual Paulista (Unesp), Via de acesso Prof. Paulo Donato Castelane, Jaboticabal, SP 14884-900, Brasil. *Autor para correspondência: anacarolina@ciave.com.br

${ }^{3}$ Docente de Técnica e Clínica Cirúrgica de Pequenos Animais, Universidade Regional de Blumenau (FURB), Rua Antônio da Veiga 140, Itoupava Seca, Blumenau, SC 89012-900, Brasil. E-mail: anapascoli@hotmail.com

${ }^{4}$ Doutoranda em Medicina Veterinária, Faculdade de Ciências Agrárias e Veterinárias (FCAV), Universidade Estadual Paulista (Unesp), Via de acesso Prof. Paulo Donato Castelane, Jaboticabal, SP 14884-900. E-mail: mary_pops1@hotmail.com

${ }^{5}$ Doutorando em Cirurgia Veterinária, Faculdade de Ciências Agrárias e Veterinárias (FCAV), Universidade Estadual Paulista (Unesp), Via de
}

acesso Prof. Paulo Donato Castelane, Jaboticabal, SP 14884-900. E-mail: nazilton@hotmail.com

${ }^{6}$ Docente da Faculdade de Ceilândia, Universidade de Brasília (UnB), Centro Metropolitano, Conjunto A, Lote 1, Brasília, DF 72220-275, Brasil. E-mail: belbiomedica@gmail.com

${ }^{7}$ Médico Veterinário autônomo, Rua Qi 6, Conjunto U, Casa 104, Guará I, Brasília, DF 71810-214. E-mail: mvetroger@gmail.com

${ }^{8}$ Docente responsável pelo Serviço de Cirurgia Veterinária, Instituto Federal Catarinense (IFC), Campus Araquari, Rodovia BR-280 Km 27, Colégio Agrícola, Araquari, SC 89245-000, Brasil. E-mail: andre.faro@ifc.edu.br

${ }^{9}$ Docente do Departamento de Clínica e Cirurgia Veterinária, Faculdade de Ciências Agrárias e Veterinárias (FCAV), Universidade Estadual Paulista (Unesp),Via de acesso Prof. Paulo Donato Castelane, Jaboticabal, SP 14884900. E-mail: andrigobarboza@yahoo.com.br 
evaluated according to Patnaik et al. (1984) ( $\mathrm{P}=0.008)$ and Kiupel et al. (2011) ( $\mathrm{P}=0.004)$. The nodules with worse prognostic feature were more frequent in animals diagnosed with multiple nodules, regardless of the histological classification used. The presence of multiple nodules in stage II or IV ( $\mathrm{p}<0.001)$ and recurrence of the disease $(\mathrm{p}=0.001)$ was also observed. Regarding the histological classification of Kiupel et al. (2011), there was a statistical association between histological grade and tumor size $(p=0.001)$, consistency $(\mathrm{p}=0.028)$ and nodule growth rate $(\mathrm{p}<0.001)$, lymph node enlargement $(\mathrm{p}<0.001)$ and the treatment used $(\mathrm{p}=0.002)$. Nodules larger than three centimeters $(56.8 \% \mathrm{n}=21)$ and fast growing $(52.9 \% \mathrm{n}=36 \%)$ were more frequent in high-grade tumors. Lymph node enlargement $(80.6 \% n=25)$ and chemotherapeutic treatment $(83.3 \% n=5)$ were also associated with patients with this histological grade. According to the classification of Patnaik et al. (1984), breed and sex differed proportionally between the histological groups $(\mathrm{p}=0.008$ and 0.040 respectively), and lymph node enlargement and rapid tumor growth were also associated with histological grade ( $\mathrm{p}=0.002$ and 0.001$)$. Almost half of the patients $(47.4 \%)$ underwent surgical and chemotherapeutic treatment $(\mathrm{n}=91)$ while only surgical procedure was performed in $31.3 \%(n=60)$ of the patients. Sixty-one animals $(31.8 \%)$ had enlarged regional lymph nodes $(31.8 \%)$, and $71.9 \%$ of the nodes evaluated had rapid growth. The clinical evolution time of the tumor was less than or equal to one year in 158 patients (82.3\%), followed by 1 to 2 years in 25 patients (13\%). There were 66 cases $(40.5 \%)$ of recurrence and $16(8.3 \%)$ of distant metastasis. With this study, it can be concluded that dogs with mixed breed are the most affected by cutaneous mastocytoma in Jaboticabal city, followed by Boxer dogs, with ages varying between 7 and 11 years, with no sexual predisposition observed. It was also concluded that nodules were predominantly non-ulcerated, solitary and smaller than 3 centimeters, that the majority of patients presented grade II mastocytoma according to Patnaik et al. (1984) and low grade according to Kiupel et al. (2011), not being observed in most of them recurrence, lymph node or distance metastasis. The most commonly used diagnosis was fine-needle aspiration associated with histopathology, and in relation to location, nodules were found predominantly in pelvic and thoracic limbs, followed by head and neck. The consistency of the nodules was both firm and soft, and half of the patients underwent the associated surgical procedure of antineoplastic chemotherapy.

INDEX TERMS: Canine, cutaneous mast, cell tumors, oncology, Jaboticabal, Brazil, neoplasm,pathology.

RESUMO.- Este estudo teve como objetivo analisar os casos de mastocitomas cutâneos em cães atendidos no Hospital Veterinário Governador Laudo Natel da Faculdade de Ciências Agrárias e Veterinárias (FCAV) Unesp Câmpus Jaboticabal, no período de 2005 a 2015, além de avaliar a ocorrência dessa neoplasia em relação à raça, sexo e idade; determinar as regiões corpóreas mais acometidas e as características neoplásicas observadas, assim como, os métodos de diagnóstico mais utilizados no setor, estabelecer os principais graus histológicos diagnosticados e os tratamentos preconizados, verificar alterações de tamanho em relação aos linfonodos, à taxa de recidiva, metástase e possíveis associações entre as variáveis consideradas. Foram avaliados 192 prontuários clínicos de pacientes e observou-se que os cães sem raça definida (SRD) $(\mathrm{n}=46,23,96 \%)$ foram os mais acometidos, seguidos por cães da raça Boxer $(n=40,20,83 \%)$ e Pit bull $(n=27,14,06 \%)$. A maioria dos cães eram fêmeas $(n=107,55,7 \%)$, e com idade de 7 a 11 anos $(n=120,62,5 \%)$. Do total, 32 pacientes apresentaram $(16,7 \%)$ tumores localizados em membro pélvico, seguidos por nódulos em membro torácico $(10,4 \%, \mathrm{n}=20)$. Sessenta e cinco animais possuíam nódulos ulcerados (33,9\%), sendo 96 nódulos de consistência firme (50\%). Setenta e seis animais apresentavam múltiplos nódulos $(39,6 \%)$ e aqueles acima de três centímetros perfaziam 39,1\% da amostra $(\mathrm{n}=75)$. 0 método mais utilizado para o diagnóstico foi a punção aspirativa por agulha fina associado à histopatologia (HT), totalizando 39,8\% dos nódulos $(\mathrm{n}=66)$, seguido pela
HT com 37,3\% (n=62). Em relação às variáveis histológicas, 18 pacientes apresentaram grau I (11,8\%), 112 com grau II $(73,7 \%)$ e 22 com grau III $(14,5 \%)$ de acordo com Patnaik et al. (1984). Segundo a classificação de Kiupel et al. (2011), 37 casos foram classificados como de alto grau (35,2\%) e 68 como sendo de baixo grau (64,8\%). Foi observada associação estatística quando se avaliou a presença de nódulos solitários/múltiplos e o grau histológico, segundo Patnaik et al. $(1984)(p=0,008)$ e Kiupel et al. (2011) ( $p=0,004)$, sendo que nódulos com piores características prognósticas eram mais frequentes nos animais diagnosticados com múltiplos nódulos, independente da classificação histológica empregada. Também foi observada a associação entre a presença de nódulos múltiplos com estadio II ou IV $(\mathrm{p}<0,001)$ e com a presença de recidiva $(\mathrm{p}=0,001)$. Em relação à classificação histológica de Kiupel et al. (2011) foi possível observar associação estatística entre o grau histológico e o tamanho do tumor ( $\mathrm{p}=0,001)$, a consistência $(\mathrm{p}=0,028)$ e a velocidade de crescimento do nódulo $(\mathrm{p}<0,001)$; aumento de linfonodo $(p<0,001)$ e o tratamento empregado $(\mathrm{p}=0,002)$. Nódulos com tamanho superior a três centímetros $(56,8 \%, \mathrm{n}=21)$ e de crescimento rápido $(52,9 \%, \mathrm{n}=36 \%)$, eram mais frequentes nos tumores de alto grau. Aumento de linfonodo $(80,6 \%, n=25)$ e tratamento quimioterápico $(83,3 \%$, $\mathrm{n}=5$ ) também estavam associados a pacientes com alto grau histológico. Em relação à classificação de Patnaik et al. (1984), as variáveis raça e sexo diferiram proporcionalmente entre os grupos histológicos ( $p=0,008$ e 0,040 respectivamente), 
sendo que o aumento do linfonodo e o crescimento rápido do tumor também tiveram associação com o grau histológico $(p=0,002$ e 0,001$)$. Quase a metade dos pacientes $(47,4 \%)$ foi submetidas ao tratamento cirúrgico e quimioterápico $(n=91)$, sendo que em $31,3 \%(n=60)$ dos pacientes realizou-se apenas o procedimento cirúrgico. Sessenta e um animais $(31,8 \%)$ apresentaram aumento de tamanho em linfonodos regionais $(31,8 \%)$, sendo que $71,9 \%$ dos nódulos avaliados tiveram crescimento rápido. 0 tempo de evolução clínica do tumor foi menor ou igual a um ano, em 158 pacientes (82,3\%), seguido por 25 pacientes (13\%) com evolução de 1 a 2 anos. Foram observados 66 casos $(40,5 \%)$ de recidiva e $16(8,3 \%)$ de metástase à distância. Com este estudo, pode-se concluir que cães sem raça definida são os mais acometidos pelo mastocitoma cutâneo, na região de Jaboticabal, seguido por cães da raça Boxer, com idade variando entre 7 e 11 anos, não sendo observada predileção sexual; os nódulos encontrados eram predominantemente não ulcerados, solitários e menores que três centímetros; a maioria dos pacientes apresentou mastocitoma grau II, segundo Patnaik et al. (1984) e baixo grau segundo Kiupel et al. (2011); não se observou recidiva, em sua maioria, nem metástase em linfonodos e/ou a distância; o diagnóstico mais utilizado foi a punção aspirativa por agulha fina associada à histopatologia; a localização dos nódulos era mais prevalente nos membros pélvicos e torácicos, seguido por cabeça e pescoço. A consistência dos nódulos era de apresentação firme ou macia; e a metade dos pacientes foi submetida ao procedimento cirúrgico associado à quimioterapia antineoplásica.

TERMOS DE INDEXAÇÃO: Mastocitoma cutâneo, caninos, oncologia, Jaboticabal, São Paulo, neoplasia, patologia.

\section{INTRODUÇÃo}

Mastocitoma corresponde à proliferação neoplásica de mastócitos, que têm origem na medula óssea e no tecido conjuntivo (Costa-Casagrande et al. 2008, Welle et al. 2008, Blackwood et al. 2012). Normalmente, os tumores cutâneos ocorrem com maior frequência em cães idosos, entre oito a dez anos (Dobson \& Scase 2007, Costa-Casagrande et al. 2008, London 2010), entretanto, já houve relatos sobre caninos jovens, com menos de seis meses (Scott et al. 1996, Aiello 1998). O local mais acometido pelo mastocitoma é a pele, embora qualquer órgão ou região do corpo possam ser afetados. 0 mastocitoma cutâneo é mais comum no tronco (50-60\%), seguido das extremidades (25-40\%), cabeça e pescoço (10\%). 0 escroto, o períneo, o dorso e a cauda são afetados com menos frequência (Welle et al. 2008). 0 aspecto macroscópico deste tumor pode mimetizar a de muitos outros tumores cutâneos, devendo o mastocitoma ser sempre considerado como diagnóstico diferencial (Dobson \& Scase 2007).

A incidência em cães é alta e representa de 11 a 15\% de todos os tumores de pele (Welle et al. 2008). É considerada, nesta espécie, a segunda neoplasia maligna mais comum, representando cerca de $20 \%$ dos casos (Costa-Casagrande et al. 2008, Welle et al. 2008, Blackwood et al. 2012).

Seu comportamento biológico é variado e imprevisível, podendo apresentar desde nodulações únicas, com comportamento benigno que podem ser tratadas apenas com ressecção cirúrgica, até massas múltiplas e metastáticas, com comportamento extremamente maligno e potencialmente fatal, e que exigem tratamento adjuvante (Dobson \& Scase 2007, Kiupel et al. 2011, Costa-Poggiani et al. 2012). Nenhum fator por si só é capaz de prever o comportamento biológico ou a resposta ao tratamento destes cães (Kiupel et al. 2011). Fatores como localização, sinais clínicos associados ao tumor, taxa de crescimento, tamanho, presença de síndromes paraneoplásicas, raça, sexo e o estadiamento clínico podem influenciar o prognóstico, entretanto, o fator mais valioso é o grau histopatológico (Welle et al. 2008, Blackwood et al. 2012). Sendo assim, os tumores bem diferenciados podem apresentar melhor prognóstico, enquanto os tumores pouco diferenciados tendem a ter prognóstico reservado (Patnaik et al. 1984). Em determinados casos, o procedimento cirúrgico pode ser curativo (Lopes 2014). No entanto, muitos tumores acabam sendo classificados em uma categoria intermediária, tornando o prognóstico de difícil determinação, com a mortalidade relacionada ao tumor, variando entre 20 e $50 \%$ (Bostock et al. 1989).

A realização da punção aspirativa com agulha fina (PAAF) de massas cutâneas e/ou subcutâneas é importante, no período pré-operatório, por auxiliar no diagnóstico da neoplasia e influenciar na decisão quanto ao tipo e extensão do procedimento, promovendo a resseção cirúrgica, com amplas margens de segurança (London et al. 1999). 0 mastocitoma é, geralmente, diagnosticado em 92 a $96 \%$ dos casos por exame citológico de esfregaços corados resultantes de PAAF's, cujos diagnósticos são posteriormente confirmados por análise histopatológica (London et al. 1999, Baker-Gabby et al. 2003, Dobson \& Scase 2007, Thamm \& Vail 2007).

Existem dois tipos de classificação histopatológica para o mastocitoma. 0 sistema de Patnaik et al. (1984) ainda é o mais utilizado para graduação do mastocitoma em cães. Contudo, o sistema de graduação em alto e baixo grau descrito por Kiupel et al. (2011) pode também tornar-se amplamente utilizado por patologistas (Blackwood et al. 2012).

Para determinar o estado clínico da doença, é necessário realizar o exame físico completo, com especial atenção à palpação dos linfonodos e presença de hepato e/ou esplenomegalia. Exames complementares, como PAAF de linfonodos, avaliação citológica de medula óssea, radiografias torácicas e ultrassonografias abdominais, podem detectar a presença e o envolvimento sistêmico da neoplasia (Rogers 1996). 0 estadiamento do tumor deve ser realizado, definindo a natureza e a extensão da doença (Blackwood et al. 2012), tendo como base o sistema TNM (tumor primário/linfonodos regionais - do inglês node e presença de metástases à distância) estabelecido pela Organização Mundial de Saúde (OMS). O sistema é amplamente utilizado, juntamente com a graduação histológica, para auxiliar no prognóstico e na seleção da terapia adequada (Welle et al. 2008).

O tratamento da neoplasia inclui a ressecção cirúrgica, radioterapia, quimioterapia antineoplásica, criocirurgia ou associação entre as modalidades, além de tratamento de suporte. A escolha do tipo de tratamento depende dos fatores prognósticos, tendo como principais pontos de apoio, a classificação histológica e o estadiamento clínico do tumor (London \& Seguin 2003, Daleck et al. 2009).

Este estudo teve como objetivo analisar os casos de mastocitomas cutâneos em cães atendidos no Hospital Veterinário Governador Laudo Natel da Faculdade de 
Ciências Agrárias e Veterinárias (FCAV), Unesp, Campus Jaboticabal, no período de 2005 a 2015, bem como, verificar a ocorrência dessa neoplasia em relação à raça, idade e sexo; determinar quais as regiões corpóreas são mais acometidas e as características neoplásicas observadas; determinar os métodos diagnósticos mais utilizados no setor de Oncologia Veterinária (SOV), no período, estabelecer os principais graus histológicos diagnosticados e os tratamentos preconizados, avaliar alterações de tamanho em relação aos linfonodos, a taxa de recidiva, a velocidade de crescimento e o tempo de evolução dos pacientes, e determinar a ocorrência de lesões metastáticas por meio do estadiamento de tumores.

\section{MATERIAL E MÉTODOS}

Foi realizado um levantamento retrospectivo dos casos de mastocitoma cutâneo canino atendidos no Hospital Veterinário “Governador Laudo Natel” (HV) da Faculdade de Ciências Agrárias e Veterinárias (FCAV), Unesp, Campus de Jaboticabal, por meio da análise em prontuários dos pacientes atendidos por profissionais do de Setor de Oncologia Veterinária (SOV), no período de 2005 a 2015. A maioria destes prontuários estava disposta em formato físico, catalogados em pastas com fichas escritas e apenas uma pequena parte informatizada. Foi obtido o termo de consentimento do uso de dados do Hospital pelo Departamento de Clínica e Cirurgia Veterinária da mesma Instituição.

Foram avaliados 192 prontuários clínicos com diagnóstico de mastocitoma cutâneo canino e obtidos dados referentes à raça, idade, sexo, tamanho do tumor (maior ou menor que três centímetros), região corpórea acometida, método diagnóstico, grau histológico, tratamento, tempo de evolução até a consulta, taxa de recidiva e metástase tumoral. Considerou-se a presença de múltiplas regiões, quando foram encontrados registros de nódulos de mastocitoma em mais de um local do corpo. Considerou-se como tempo de evolução da neoplasia o período que consistiu entre o registro do aparecimento do tumor e o primeiro atendimento realizado pelo SOV.

Os métodos diagnósticos utilizados foram a punção aspirativa com agulha fina (PAAF) e/ou a histopatologia (HT), tendo sido realizada, em determinados pacientes, apenas a PAAF ou a HT, por opção financeira do tutor, e em outros, a PAAF como triagem e a HT como diagnóstico definitivo. No que se refere ao grau histológico do mastocitoma, seguiu-se o descrito por Patnaik et al. (1984), ou seja, a classificação da afecção em graus I, II e III. Adicionalmente, utilizou-se a classificação de Kiupel et al. (2011), a qual divide os mastocitomas em alto e baixo grau, em pacientes atendidos, a partir de 2012. Quanto ao tipo de tratamento, incluíram-se a intervenção cirúrgica e a quimioterapia antineoplásica, associadas ou não, e a ausência de tratamento. Vale salientar que as duas últimas resultaram da decisão dos tutores em interromper e/ou não iniciar a terapia.

Em relação às metástases, os animais foram avaliados por meio de radiografias de tórax e ultrassonografia abdominal. Animais livres de metástase à distância receberam classificação M0, enquanto, animais que apresentaram exames de imagem com presença de nódulos metastáticos, foram classificados como M1. Quanto aos linfonodos, animais que durante o exame clínico apresentaram aumento no tamanho dos linfonodos regionais foram classificados como N1, enquanto, animais sem aumento de linfonodos regionais foram classificados como N0. Em razão de nem todos os prontuários clínicos terem apresentado informações relacionadas à citologia dos linfonodos, avaliou-se, neste estudo, somente alterações dimensionais (tamanho e forma) e morfológicas (aspecto e consistência), dedutíveis por palpação e paquimetria.
O estadio do paciente obedeceu ao sistema de estadiamento clínico para o mastocitoma canino, estabelecido pela Organização Mundial da Saúde (OMS). Foram excluídos desse estudo os pacientes que apresentavam prontuários não preenchidos e/ou com dados incompletos.

Para a análise estatística, os dados de cada variável foram agrupados em categorias. Os dados foram descritos em termos de frequência absoluta e relativa. Para estudo da associação entre as variáveis, aplicou-se o teste Qui-quadrado. 0 nível de significância adotado foi de $5 \%(p<0,05)$ e o software estatístico utilizado foi o SPSS Versão 20.0 .

\section{RESULTADOS}

Em relação à raça, foi observado que os cães sem raça definida (SRD) $(n=46,23,96 \%)$ foram os mais acometidos, seguidos por cães da raça Boxer ( $n=40,20,83 \%)$ e Pit Bull $(n=27,14,06 \%)$. A maioria dos cães era fêmea $(n=107,55,7 \%)$, e com idades variando de 7 a 11 anos $(n=120,62,5 \%)$, conforme descrito no Quadro 1.

Dentre as variáveis clínicas avaliadas, referência ao Quadro 2 que 65 animais apresentavam nódulos ulcerados (33,9\%), sendo 96 nódulos de consistência firme (50\%). Setenta e seis animais apresentavam múltiplos nódulos $(39,6 \%)$, os nódulos acima de três centímetros perfaziam 39,1\% da amostra $(n=75)$ e sessenta e um animais (31,8\%) apresentaram aumento de tamanho em linfonodos regionais, N1 (31,8\%).

Com o emprego do Sistema de Estadiamento Clínico para o mastocitoma canino proposto pela OMS, verificou-se que os mastocitomas associados com a presença de lesões

Quadro 1. Distribuição das variáveis epidemiológicas em número relativo (N) e absoluto (\%) dos cães com mastocitoma cutâneo atendidos no Hospital Veterinário Governador Laudo Natel, FCAV-Unesp, Jaboticabal, de 2005 a 2015

\begin{tabular}{|c|c|c|c|}
\hline & Variável & $\mathrm{N}$ & $\%$ \\
\hline \multirow[t]{17}{*}{ Raça } & Boxer & 40 & $20,83 \%$ \\
\hline & Labrador Retriever & 18 & $9,4 \%$ \\
\hline & American Pit Bull & 27 & $14,06 \%$ \\
\hline & Pinscher & 14 & $7,3 \%$ \\
\hline & Beagle & 1 & $0,5 \%$ \\
\hline & Bernesse Montain dog & 1 & $0,5 \%$ \\
\hline & Cocker Spaniel & 2 & $1,0 \%$ \\
\hline & Teckel & 4 & $6,6 \%$ \\
\hline & Dogue Alemão & 2 & $1,0 \%$ \\
\hline & Fila & 3 & $1,6 \%$ \\
\hline & Fox Paulistinha & 3 & $1,6 \%$ \\
\hline & Mastim Napolitano & 1 & $0,5 \%$ \\
\hline & Outras & 21 & $10,9 \%$ \\
\hline & Akita & 1 & $0,5 \%$ \\
\hline & Rottweiler & 5 & $2,6 \%$ \\
\hline & SRD & 46 & $23,96 \%$ \\
\hline & Poodle & 3 & $1,6 \%$ \\
\hline \multirow[t]{2}{*}{ Sexo } & Macho & 85 & $44,3 \%$ \\
\hline & Fêmea & 107 & $55,7 \%$ \\
\hline \multirow[t]{3}{*}{ Idade } & 2 a 6 anos & 39 & $20,3 \%$ \\
\hline & 7 a 11 anos & 120 & $62,5 \%$ \\
\hline & 12 a 16 anos & 33 & $17,2 \%$ \\
\hline
\end{tabular}


metastáticas ou com recidiva associada à ocorrência de metástases (incluindo envolvimento sanguíneo ou da medula óssea - estadiamento IV) totalizavam $8,3 \%$ dos cães estudados $(n=16)$, sendo que $71,9 \%$ dos nódulos avaliados tiveram crescimento rápido.

O tempo de evolução clínica do tumor foi menor ou igual a um ano em 158 pacientes (82,3\%), seguido por 25 pacientes $(13 \%)$ entre 1 e 2 anos. Quase a metade dos pacientes $(47,4 \%)$ foi submetida ao tratamento cirúrgico e quimioterápico $(n=91)$, sendo que em $31,3 \%(n=60)$ dos pacientes foram realizados apenas o procedimento cirúrgico. Dos 192 cães do estudo, apenas 23 deles (13,1\%) já haviam sido atendidos anteriormente por outro serviço veterinário. Foram observados 66 casos $(40,5 \%)$ de recidiva e $16(8,3 \%)$ de metástase à distância, diagnosticada por meio de exames radiográficos e ultrassonográficos. Em relação às variáveis histológicas, podemos observar as frequências absolutas e

Quadro 2. Distribuição das variáveis clínicas em número relativo (N) e absoluto (\%) dos cães com mastocitoma cutâneo atendidos no Hospital Veterinário Governador Laudo Natel, FCAV-Unesp, Jaboticabal, de 2005 a 2015

\begin{tabular}{|c|c|c|c|}
\hline \multicolumn{2}{|c|}{ Variável } & \multirow{2}{*}{$\frac{N}{65}$} & \multirow{2}{*}{$\frac{\%}{33,9 \%}$} \\
\hline Ulceração & Sim & & \\
\hline & Não & 127 & $66,1 \%$ \\
\hline \multirow[t]{2}{*}{ Consistência } & Macia & 96 & $50,0 \%$ \\
\hline & Firme & 96 & $50,0 \%$ \\
\hline \multirow[t]{2}{*}{ Nódulos } & Múltiplos & 76 & $39,6 \%$ \\
\hline & Solitário & 116 & $60,4 \%$ \\
\hline \multirow[t]{2}{*}{ Tamanho } & $>3 \mathrm{~cm}$ & 75 & $39,1 \%$ \\
\hline & $<3 \mathrm{~cm}$ & 117 & $60,9 \%$ \\
\hline \multirow[t]{2}{*}{ Linfonodo } & N0 & 131 & $68,2 \%$ \\
\hline & N1 & 61 & $31,8 \%$ \\
\hline \multirow[t]{2}{*}{ Metástase } & M0 & 176 & $91,7 \%$ \\
\hline & M1 & 16 & $8,3 \%$ \\
\hline \multirow[t]{4}{*}{ Estadio } & I & 69 & $35,94 \%$ \\
\hline & II & 34 & $17,71 \%$ \\
\hline & III & 73 & $38,02 \%$ \\
\hline & IV & 16 & $8,33 \%$ \\
\hline \multirow{4}{*}{$\begin{array}{l}\text { Tempo de } \\
\text { Evolução }\end{array}$} & $>=1$ ano & 158 & $82,30 \%$ \\
\hline & 1 a 2 anos & 25 & $13,00 \%$ \\
\hline & 2 a 3 anos & 5 & $2,60 \%$ \\
\hline & $>3$ anos & 4 & $2,10 \%$ \\
\hline \multirow[t]{2}{*}{ Recidiva } & $\operatorname{Sim}$ & 66 & $40,50 \%$ \\
\hline & Não & 97 & $59,50 \%$ \\
\hline \multirow{2}{*}{$\begin{array}{l}\text { Tratamento } \\
\text { prévio }\end{array}$} & Sim & 23 & $13,10 \%$ \\
\hline & Não & 153 & $86,90 \%$ \\
\hline \multirow[t]{4}{*}{ Tratamento } & Cirurgia & 60 & $31,30 \%$ \\
\hline & Cirurgia + QT & 91 & $47,40 \%$ \\
\hline & Sem Tratamento & 27 & $14,10 \%$ \\
\hline & QT & 14 & $7,30 \%$ \\
\hline \multirow{2}{*}{$\begin{array}{l}\text { Velocidade de } \\
\text { crescimento }\end{array}$} & Rápido & 138 & $71,90 \%$ \\
\hline & Lento & 54 & $28,10 \%$ \\
\hline
\end{tabular}

QT = Quimioterapia antineoplásica, N0 = sem comprometimento macroscópico de linfonodos, N1 = aumento dos linfonodos regionais, M0 = animais sem metástase à distância, M1 = presença de nódulos metastáticos. relativas, segundo os prontuários avaliados. Vale ressaltar que nem todos os pacientes foram avaliados histologicamente, devido a situação econômica do tutor. Dezoito pacientes foram classificados com grau I (11,8\%), 112 com grau II $(73,7 \%)$ e 22 casos de mastocitomas de grau III $(14,5 \%)$ de acordo com Patnaik et al. (1984). Segundo a classificação de Kiupel et al. (2011), 37 casos foram classificados como de alto grau $(35,2 \%)$ e 68 como baixo grau $(64,8 \%)$. 0 método mais utilizado para o diagnóstico do mastocitoma foi punção aspirativa por agulha fina (PAAF) associado com histopatologia (HT), totalizando $39,8 \%$ dos nódulos $(n=66)$, seguido pela HT com 37,3\% (n=62) (Quadro 3).

A distribuição das localizações dos tumores está representada na figura 1 . Destes, $16,7 \%(n=32)$ estavam localizados em membro pélvico, seguido por nódulos em membro torácico $(10,4 \% ; n=20)$. As localizações dos nódulos cuja frequência relativa era inferior a $5 \%$ foram agrupados na categoria outros $(26,6 \%)$. Os nódulos referentes à região abdominal indicam a região cutânea e não nódulos cavitários.

Pelo teste de quiquadrado, não houve associação estatística entre a presença de nódulos múltiplos e solitários e as variáveis sexo $(\mathrm{p}=0,432)$, idade do animal $(\mathrm{p}=0,985)$, presença de ulceração $(p=0,933)$, consistência $(p=0,376)$, velocidade do crescimento $(p=0,652)$, tamanho do nódulo $(p=0,935)$, linfonodo $\mathrm{N} 1(\mathrm{p}=0,787)$, metástases $(\mathrm{p}=0,374)$, tempo de evolução $(p=0,773)$, tratamento aplicado $(p=0,771)$ e método

Quadro 3. Distribuição das variáveis histológicas e métodos utilizados para diagnóstico em número relativo $(\mathrm{N})$ e absoluto (\%) de cães com mastocitoma cutâneo atendidos no Hospital Veterinário Governador Laudo Natel, FCAV-Unesp, Jaboticabal, de 2005 a 2015

\begin{tabular}{lccc}
\hline \multicolumn{1}{c}{ Variável } & & $\mathrm{N}$ & $\%$ \\
\hline Grau histopatológico segundo & I & 18 & $11,80 \%$ \\
Patnaik et al. (1984) & II & 112 & $73,70 \%$ \\
& III & 22 & $14,50 \%$ \\
Grau histopatológico segundo & Alto & 37 & $35,20 \%$ \\
Kiupel et al. (2011) & Baixo & 68 & $64,80 \%$ \\
Método Diagnóstico & PAAF & 38 & $22,90 \%$ \\
& HT & 62 & $37,30 \%$ \\
& PAAF/HT & 66 & $39,80 \%$
\end{tabular}

PAAF = punção aspirativa por agulha fina, $\mathrm{HT}=$ histopatológico.

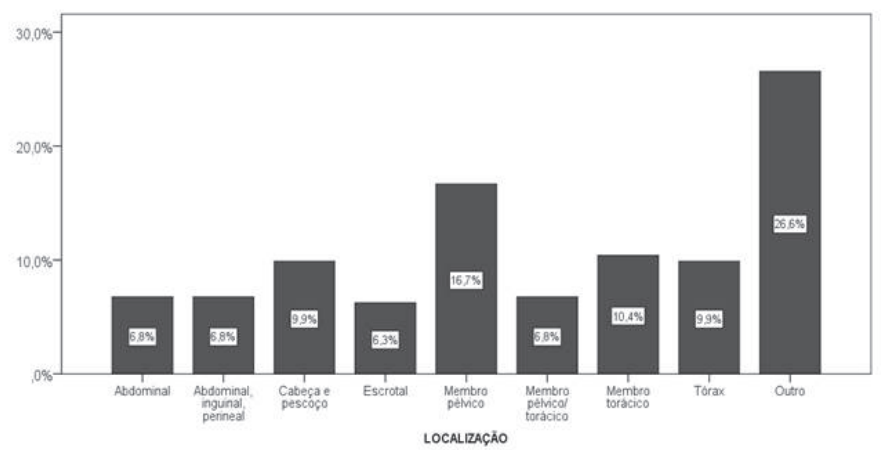

Fig.1. Distribuição dos registros conforme a localização dos mastocitomas em cães que foram atendidos no Hospital Veterinário Governador Laudo Natel, FCAV-Unesp, Jaboticabal, de 2005 a 2015. 
diagnóstico ( $p=0,0504)$. Destaca-se que a relação entre animais diagnosticados com nódulos múltiplos e nódulos solitários foi de, aproximadamente, 2:3.

A associação estatística foi observada apenas quando se avaliou a presença de nódulos solitários/múltiplos e o grau histológico segundo Patnaik et al. (1984), $(\mathrm{p}=0,008)$ e Kiupel et al. (2011), ( $\mathrm{p}=0,004)$, sendo que nódulos com piores prognósticos eram mais frequentes nos animais diagnosticados com múltiplos nódulos, independente da classificação histológica empregada. Também foi observada a associação entre a presença de nódulos múltiplos com estadio II ou IV $(\mathrm{p}<0,001)$ e com a presença de recidiva $(\mathrm{p}=0,001)$ (Quadro 4).

Por outro lado, o Quadro 5 descreve a análise da associação das variáveis epidemiológicas, clínicas e histológicas dos animais estudados, de acordo com a classificação histológica de Kiupel et al. (2011). Foi possível observar associação estatística entre o grau histológico e o tamanho do tumor $(\mathrm{p}=0,001)$, a consistência $(p=0,028)$ e a velocidade de crescimento nódulo $(\mathrm{p}<0,001)$, aumento de linfonodo $\mathrm{N} 1(\mathrm{p}<0,001)$ e o tratamento empregado ( $\mathrm{p}=0,002)$. Nódulos com dimensão que ultrapassavam três centímetros $(56,8 \%, \mathrm{n}=21)$ e de crescimento rápido $(52,9 \%, n=36 \%)$, foram mais frequentes nos tumores de alto grau. Aumento de linfonodos N1 $(80,6 \%, n=25)$ e tratamento quimioterápico $(83,3 \%, n=5)$ também estavam associados a pacientes com este grau histológico. As demais comparações entre variáveis não foram estatisticamente significantes.

O Quadro 6 demonstra as associações epidemiológicas, clínicas e histológicas dos animais, conforme a classificação de Patnaik et al. (1984). Nessa, as variáveis raça e sexo diferem, proporcionalmente, entre os grupos histológicos ( $p=0,008$ e 0,040, respectivamente). Aumento do tamanho do linfonodo (N1) e velocidade de crescimento rápido também tiveram associação com o grau histológico ( $p=0,002$ e 0,001).

Quadro 4. Distribuição das variáveis epidemiológicas, clínicas e histológicas em número relativo (N) e absoluto (\%) dos cães com mastocitoma cutâneo e atendidos no Hospital Veterinário Governador Laudo Natel, FCAV-Unesp, Jaboticabal, de 2005 a 2015, conforme presença de nódulo solitário ou múltiplos

\begin{tabular}{|c|c|c|c|c|c|c|c|c|}
\hline & & \multicolumn{6}{|c|}{ Nódulos } & \multirow{3}{*}{$\mathrm{p}$} \\
\hline & & \multicolumn{2}{|c|}{ Múltiplos } & \multicolumn{2}{|c|}{ Solitário } & \multicolumn{2}{|c|}{ Total } & \\
\hline & & $\mathrm{N}$ & $\%$ & $\mathrm{~N}$ & $\%$ & $\mathrm{~N}$ & $\%$ & \\
\hline \multirow{3}{*}{$\begin{array}{l}\text { Grau HP segundo Patnaik et al. } \\
\text { (1984) }\end{array}$} & I & 5 & $27,8 \%$ & 13 & $72,2 \%$ & 18 & $100,0 \%$ & $0,008^{*}$ \\
\hline & II & 39 & $34,8 \%$ & 73 & $65,2 \%$ & 112 & $100,0 \%$ & \\
\hline & III & 15 & $68,2 \%$ & 7 & $31,8 \%$ & 22 & $100,0 \%$ & \\
\hline \multirow{2}{*}{$\begin{array}{l}\text { Grau HP segundo Kiupel et al. } \\
\text { (2011) }\end{array}$} & Alto & 21 & $56,8 \%$ & 16 & $43,2 \%$ & 37 & $100,0 \%$ & $0,004^{*}$ \\
\hline & Baixo & 19 & $27,9 \%$ & 49 & $72,1 \%$ & 68 & $100,0 \%$ & \\
\hline \multirow[t]{2}{*}{ Recidiva } & Sim & 32 & $48,5 \%$ & 34 & $51,5 \%$ & 66 & $100,0 \%$ & $0,001^{*}$ \\
\hline & Não & 28 & $28,9 \%$ & 69 & $71,7 \%$ & 97 & $100,0 \%$ & \\
\hline \multirow[t]{2}{*}{ Estadio } & III ou IV & 67 & $75,3 \%$ & 22 & $24,7 \%$ & 89 & $100,0 \%$ & $<0,001^{*}$ \\
\hline & I ou II & 9 & $8,7 \%$ & 94 & $91,3 \%$ & 103 & $100,0 \%$ & \\
\hline
\end{tabular}

* Teste do qui-quadrado, $p<0,05$.

Quadro 5. Distribuição das variáveis epidemiológicas, clínicas e histológicas em número relativo (N) e absoluto (\%) dos cães com mastocitoma cutâneo e atendidos no Hospital Veterinário Governador Laudo Natel, FCAV-Unesp, Jaboticabal, de 2005 a 2015, de acordo com a classificação de Kiupel et al. (2011)

\begin{tabular}{|c|c|c|c|c|c|c|c|c|}
\hline & & \multicolumn{6}{|c|}{ Grau HT segundo Kiupel et al. (2011) } & \multirow{3}{*}{$\mathrm{p}$} \\
\hline & & \multicolumn{2}{|c|}{ Alto } & \multicolumn{2}{|c|}{ Baixo } & \multicolumn{2}{|c|}{ Total } & \\
\hline & & $\mathrm{N}$ & $\%$ & $\mathrm{~N}$ & $\%$ & $\mathrm{~N}$ & $\%$ & \\
\hline Consistência & Firme & 23 & $46,0 \%$ & 27 & $54,0 \%$ & 50 & $100,0 \%$ & $0,028^{*}$ \\
\hline \multirow[t]{2}{*}{ Tamanho } & $>3 \mathrm{~cm}$ & 21 & $56,8 \%$ & 16 & $43,2 \%$ & 37 & $100,0 \%$ & $0,001^{*}$ \\
\hline & $<3 \mathrm{~cm}$ & 16 & $23,5 \%$ & 52 & $76,5 \%$ & 68 & $100,0 \%$ & \\
\hline \multirow[t]{4}{*}{ Tratamento } & Sem tratamento & 0 & $0,0 \%$ & 0 & $0,0 \%$ & 0 & $0,0 \%$ & $0,002^{*}$ \\
\hline & Cirurgia & 6 & $16,7 \%$ & 30 & $83,3 \%$ & 36 & $100,0 \%$ & \\
\hline & QT & 5 & $83,3 \%$ & 1 & $16,7 \%$ & 6 & $100,0 \%$ & \\
\hline & Cirurgia + QT & 26 & $41,3 \%$ & 37 & $58,7 \%$ & 63 & $100,0 \%$ & \\
\hline Velocidade de crescimento & Rápido & 36 & $52,9 \%$ & 32 & $47,1 \%$ & 68 & $100,0 \%$ & $<0,001^{*}$ \\
\hline
\end{tabular}

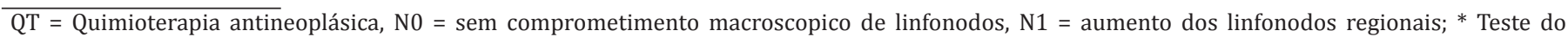
qui-quadrado, $p<0,05$. 
Quadro 6. Distribuição das variáveis epidemiológicas, clínicas e histológicas em número relativo (N) e absoluto (\%) dos cães com mastocitoma cutâneo e atendidos no Hospital Veterinário Governador Laudo Natel, FCAV-Unesp, Jaboticabal, de 2005 a 2015, de acordo com a classificação de Patnaik et al. (1984)

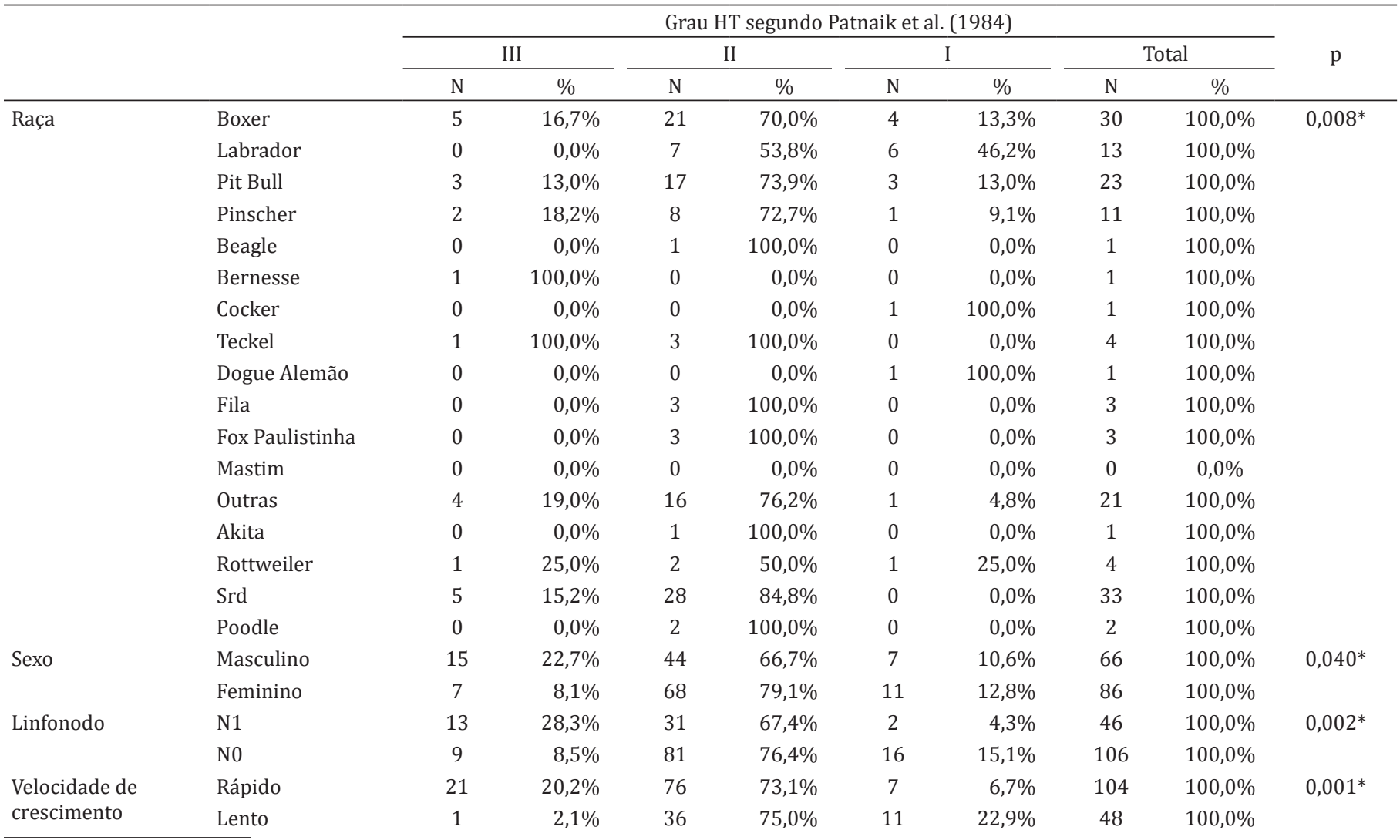

$\overline{\mathrm{N} 0}=$ sem comprometimento macroscópico de linfonodos, N1 = aumento dos linfonodos regionais; * Teste do qui-quadrado, $p<0,05$.

\section{DISCUSSÃO}

Em relação ao sexo, não houve diferença estatística significante entre fêmeas $(55,7 \%)$ e machos $(44,3 \%)$, em consonância com vários autores que afirmam que nenhum estudo até o momento determinou a prevalência relacionada ao sexo (Stannard \& Pulley 1990, Ogilvie \& Moore 1995, Scott et al. 1996, London \& Seguin 2003, Thamm \& Vail 2007, Costa-Casagrande et al. 2008), embora alguns autores relatam maior incidência em fêmeas, fêmeas castradas e machos intactos (Simões et al. 1994). Em um estudo desenvolvido por Kiupel et al. (2011), os machos idosos apresentaram tempos de sobrevida inferiores às fêmeas; os pacientes da raça Boxer e os idosos demonstraram maior frequência em desenvolver mastocitomas múltiplos.

Foi observada maior ocorrência de mastocitoma em cães com idade de 7 a 11 anos (62,5\%), similar a dados encontrados por autores que afirmam maior frequência de neoplasias cutâneas em cães idosos, entre oito e dez anos (Dobson \& Scase 2007, London 2010). Costa-Casagrande et al. (2008) verificaram maior prevalência em cães com 9 a 11 anos, apesar de já terem sido relatados em caninos jovens, com menos de seis meses de idade (Scott et al. 1996, Aiello 1998).

Em relação às raças dos animais acometidos pelo mastocitoma, foi verificada maior predisposição em cães SRD (23,96\%), seguida da raça Boxer (20,83\%). Apesar dos cães SRD não serem os mais citados na literatura, a maior incidência destes pode estar relacionada à predominância da casuística do Hospital Veterinário. Gilson e Page (1998) observaram em estudos que os mastocitomas envolvem, principalmente, cães braquicefálicos, convergindo com os achados deste trabalho que demonstra o Boxer como uma das raças mais acometidas. Costa-Casagrande etal. (2008) em estudo realizado em São Paulo, encontraram prevalência de $38,8 \%$ em cães da raça Boxer, seguido por cães SRD (26,5\%). Em relação à incidência em cães da raça Boxer, os resultados reforçam os achados de diversos autores que afirmam ser essa uma das raças predispostas ao mastocitoma (Madewell \& Theilen 1987, Gross et al. 1992, Kummel 1996, Scott et al. 1996, Warland \& Dobson 2013, Miller et al. 2014). Entretanto, Ogilvie \& Moore (1995) afirmam que o mastocitoma nessa raça apresenta-se com menor grau de malignidade. Ainda, acredita-se que pacientes da raça Boxer sejam portadores de oncogenes que possam ser transmitidos aos seus descendentes e em combinação à deficiência imunológica; tal associação de fatores genéticos explicaria a alta incidência da doença nesses animais (Scott et al. 1996).

Do total de 192 animais estudados, foi possível determinar que as regiões corpóreas mais acometidas foram os membros pélvicos (16,7\%), seguido pelos membros torácicos $(10,42 \%)$, cabeça e pescoço $(9,46 \%)$, o que também foi observado por Costa-Poggiani et al. (2012). Já Welle et al. (2008) afirmam ser o mastocitoma cutâneo mais comumente encontrado no tronco (50-60\%), seguido das extremidades (25-40\%), 
cabeça e pescoço (10\%). Dobson et al. (2004) e Navega (2011) afirmam que os tumores na cabeça estão associados a um pior prognóstico, quando comparados com os que se originam nos membros, porém, London \& Seguin (2003) afirmam ausência de evidências definitivas sobre quais regiões do corpo estariam associadas a comportamento mais maligno. No entanto, nesse estudo, o grau de malignidade não foi relacionado com a localização do corpo.

Em relação às variáveis clínicas, 65 animais possuíam nódulos ulcerados (33,9\%), sendo a ulceração, o eritema e o prurido associados a tumores de pior prognóstico (Thamm et al. 1999, Mullins et al. 2006). Mastocitomas caninos têm sido observados originando-se a partir de dermatites ou lesões crônicas (Couto 2001).

Cento e dezesseis animais apresentavam nódulos solitários $(60,4 \%)$ e $50 \%$ desses apresentavam consistência firme, como nos achados de Dobson \& Scase (2007), que afirmam que o mastocitoma cutâneo, normalmente, se manifesta por lesão solitária e sólida.

Os nódulos acima de três centímetros totalizaram 39,1\% dos casos, sendo esses os tumores com pior prognóstico, corroborando com os dados obtidos no estudo realizado por Mullins et al. (2006). Dos pacientes desse estudo, 71,9\% deles apresentaram nódulos com crescimento rápido, possuindo pior prognóstico (Vail 1996, Thamm \& Vail 2007, Welle et al. 2008). Para Macy (1985), a velocidade de crescimento é o que determina o comportamento biológico do mastocitoma canino e não o tamanho do tumor.

Foi observado que os pacientes com mastocitomas associados com a presença de lesões metastáticas (estadiamento IV), totalizavam 8,3\% dos cães; 71 animais apresentaram aumento de tamanho dos linfonodos regionais (31,8\%); e 66 pacientes $(40,5 \%)$ apresentaram recidivas, estando as pós-cirúrgicas associadas a prognósticos reservados (Thamm \& Vail 2007), assim como as metástases em linfonodos (Thamm et al. 2006). Macy (1985) cita que a taxa de mortalidade de cães com mastocitoma associadas à recidiva ou metástases varia de 13 a 94\%, dependendo da classificação histológica. Não foram encontrados dados relacionados à PAAF dos linfonodos regionais em todos os prontuários. Acredita-se que era realizada nos pacientes que apresentavam o órgão com alterações perceptíveis ao exame de palpação, porém, atualmente, no Serviço de Oncologia da UNESP, Câmpus Jaboticabal, é realizada PAAF nos linfonodos regionais de pacientes com mastocitomas cutâneos como padrão para identificação precoce de possíveis metástases,

0 tempo de evolução clínica do tumor foi de um ano em 158 pacientes $(82,3 \%)$, seguido por 25 pacientes $(13 \%)$ que apresentaram evolução de 1 a 2 anos. London \& Seguin (2003) citam que nem sempre o tempo de evolução das lesões permite estimar o comportamento biológico do mastocitoma.

Quase a metade dos pacientes $(47,4 \%)$ foi submetida ao tratamento cirúrgico e quimioterápico antineoplásico, sendo que em $31,3 \%$ desses foram realizados apenas o procedimento cirúrgico. Miller et al. (2014) demonstraram que o tratamento cirúrgico acompanhado de quimioterapia antineoplásica apresentou sobrevida de 278 dias, quando comparado ao tratamento único de quimioterapia (vimblastina e prednisolona), com sobrevida de 91 dias. Hahn et al. (2010) também demonstraram em estudo que o uso de masitinib aumenta a sobrevida em cães com mastocitoma não resseccionável grau II e III. Catorze animais realizaram como tratamento apenas o protocolo de quimioterapia antineoplásica. Cabe salientar que a quimioterapia antineoplásica como tratamento isolado é indicado em casos de tumores disseminados para promover citorredução (Rogers 1996), bem como, em situações de mastocitomas de grau elevado ou não determinado, onde a cirurgia não pode ser realizada (London \& Seguin 2003).

Em relação ao método mais utilizado para o diagnóstico do mastocitoma, a PAAF associada à histopatologia (HT), totalizou $39,8 \%$ dos casos, seguida pela HT como único método diagnóstico, com 37,3\%. A PAAF é um excelente método diagnóstico para os tumores de células redondas, segundo autores (Aiello 1998, Elmslie 2003, London \& Seguin 2003, Rocha et al. 2004), sendo indicada a HT para classificá-los quanto ao grau histológico (London \& Seguin 2003, Costa-Casagrande et al. 2008).

Em relação às variáveis histológicas, 11,8\% dos pacientes apresentaram mastocitoma grau I, 73,7\% grau II e 14,5\% grau III, de acordo com Patnaik et al. (1984). Diferentes dados foram obtidos por Furlani (2008), avaliando mastocitomas, também no Hospital Veterinário Governador Laudo Natel da Unesp, Câmpus Jaboticabal, entre 2001-2004, que determinou que $36,67 \%(n=30)$ eram grau I, 33,33\% grau II e $30 \%$ grau III. Patnaik et al. (1984) afirmam que os mastocitomas grau I representam de 30 a 55\% dos casos; grau II, de 25 a 45\%, e os de grau III, de 20 a 40\%. Segundo alguns autores, o mastocitoma grau I apresenta comportamento benigno, sendo que a excisão cirúrgica pode resultar em cura (Patnaik et al. 1984, London \& Seguin 2003).

Segundo a classificação de Kiupel et al. (2011), 35,2\% apresentaram alto grau e $64,8 \%$ baixo grau. No presente estudo, todos os mastocitomas grau I, segundo Patnaik et al. (1984), foram classificados como baixo grau $(n=7)$, segundo Kiupel et al. (2011), 90\% ( $n=63)$ dos graduados como II foram classificados como baixo grau; e $10 \%(n=7)$ foram classificados como alto grau. Dentre os tumores graduados como grau III ( $n=11), 10$ foram classificados como alto grau e apenas 1 como baixo grau. A classificação histológica é o fator prognóstico mais consistente na avaliação de cães com mastocitoma e está relacionado à sobrevida, porém, não permite estimar o comportamento tumoral em todos os pacientes (Patnaik et al. 1984). Mastocitomas de alto grau foram associadas ao menor tempo livre de doença ou desenvolvimento de novo tumor, e com menor tempo de sobrevida (Kiupel et al. 2011).

\section{CONCLUSÕES}

Com este estudo, pode-se concluir que cães sem raça definida são os mais acometidos pelo mastocitoma cutâneo, na região de Jaboticabal, seguido por cães da raça Boxer, com idade variando de 7 a 11 anos, não sendo observada prevalência sexual.

Os nódulos são predominantemente não ulcerados, solitários e menores que três centímetros.

A maioria dos cães apresenta mastocitoma grau II e baixo grau, não sendo observada recidiva em sua maioria, nem metástase em linfonodos e a distância.

0 diagnóstico mais utilizado ocorreu por punção aspirativa por agulha fina associada ao exame histopatológico.

A maior frequência de apresentação dos nódulos foi em membros pélvicos e torácicos, seguido por cabeça e pescoço, respectivamente. 
A consistência dos nódulos foi tanto firme quanto macia, e a metade dos pacientes foi submetida ao procedimento cirúrgico associado à quimioterapia antineoplásica.

\section{REFERÊNCIAS}

Aiello S.E. 1998. The Merck Veterinary Manual. 8th ed. National Publishing, Philadelphia.

Baker-Gabby M., Hunt G.B. \& France M.P. 2003. Soft tissue sarcomas and mast cell tumours in dogs: clinical behaviour and response to surgery. Aust. Vet. J. 81(12):732-738. <http://dx.doi.org/10.1111/j.1751-0813.2003. tb14601.x><PMid:15080482>

Blackwood L., Murphy S., Buracco P., De Vos J.P., De Fornel-Thibaud P., Hirschberger J., Kessler M., Pastor J., Ponce F., Savary-Bataille K. \& Argyle D.J. 2012. European consensus document on mast cell tumours in dogs and cats. Vet. Comp. Oncol.10(3):1-29. <http://dx.doi.org/10.1111/j.1476-5829.2012.00341. $\mathrm{x}><$ PMid:22882486>

Bostock D.E., Crocker J., Harris K. \& Smith P. 1989. Nucleolar organizer regions as indicators of post-surgical prognosis in canine spontaneous mast cell tumours. Brit. J. Cancer 59(6):915-918. <http://dx.doi.org/10.1038/ bjc.1989.193> <PMid:2500145>

Costa-Casagrande T.A., Elias D.S., Melo S.R. \& Matera J.M. 2008. Estudo retrospectivo do mastocitoma canino no serviço de cirurgia de pequenos animais, Hospital Veterinário da Faculdade de Medicina Veterinária e Zootecnia da Universidade de São Paulo. Arch. Vet. Sci. 13(3):176-183. <http://dx.doi.org/10.5380/avs.v13i3.11667>

Costa-Poggiani S.S., Terra E.M., Torres-Neto R., Tinucci-Costa M. \& Amorin R.L. 2012. Canine cutaneous mast cell tumor: biologic behavior and its correlation with prognostic indicators. Open. J. Vet. Med. 2(04):255-261. <http://dx.doi.org/10.4236/ojvm.2012.24041>

Couto C.G. 2001. Neoplasia selecionadas em cães e gatos, p.897-908. In: Nelson R.W. \& Couto C.G. (Eds), Medicina Interna de Pequenos Animais. $2^{a}$ ed. Guanabara Koogan. Rio de Janeiro.

Daleck C.R., De Nardi A.B. \& Rodaski S. 2009. Mastocitoma, p.282-292 In: Daleck C.R., De Nardi A.B. \& Rodaski S. (Eds), Oncologia em Cães e Gatos: Roca, São Paulo.

Dobson J.M. \& Scase T. 2007. Advances in the diagnosis and management of cutaneous mast cell tumours in dogs. J. Small. Anim. Pract. 48(8):424-431. <http://dx.doi.org/10.1111/j.1748-5827.2007.00366.x><PMid:17559522>

Dobson J.M., Cohen S. \& Gould S. 2004. Treatment of canine mast cell tumours with prednisolone and radiotherapy. Vet. Comp. Oncol 2(3):132-141. <http://dx.doi.org/10.1111/j.1476-5810.2004.00048.x><PMid:19379301>

Elmslie R.E. 2003. Mastocitoma, p.14-23. In: Tilley L.P. \& Smith F.K. (Eds), Consulta Veterinária em 5 Minutos: espécies canina e felina. Manole, Barueri.

Furlani J.M., Daleck C.R., Vicenti F.A.M., De Nardi A.B., Pereira G.T., Santana A.E., Eurides D. \& Silva L.A.F. 2008. Mastocitoma canina: estudo retrospectivo. Ciênc. Anim. Bras. 9(1):242-250.

Gilson S.D. \& Page R.L. 1998. Princípios de oncologia, p.209-217. In: Birchard S.J. \& Sherding R.G. (Eds), Manual Saunders: clinica de pequenos animais: Roca, São Paulo.

Gross L.T., Ihrhe P.J. \& Walder E.J. 1992. Veterinary Dermatopathology: a macroscopic and microscopic evaluation of canine and felines skin disease. Mosby, St Louis. 519p.

Hahn K.A., Legendre A.M., Shaw N.G., Phillips B., Ogilvie G.K., Prescott D.M., Atwater S.W., Carreras J.K., Lana S.E., Ladue T., Rusk A., Kinet J.P., Dubreuil P., Moussy A. \& Hermine 0. 2010. Evaluation of 12- and 24-month survival rates after treatment with masitis in dogs with nonresectable mast cell tumors. Am. J. Vet. Res. 71(11):1354-1361. <http://dx.doi.org/10.2460/ ajvr.71.11.1354><PMid:21034327>

Kiupel M., Webster J.D., Bailey K.L., Best S., DeLay J., Detrisac C.J., Fitzgerald S.D., Gamble D., Ginn P.E., Goldschmidt M.H., Hendrick M.J., Howerth E.W.,
Janovitz E.B., Langohr I., Lenz S.D., Lipscomb T.P., Miller M.A., Misdorp W., Moroff S., Mullaney T.P., Neyens I., O’Toole D., Ramos-Vara J., Scase T.J., Schulman F.Y., Sledge D., Smedley R.C., Smith K., W Snyder P., Southorn E., Stedman N.L., Steficek B.A., Stromberg P.C., Valli V.E., Weisbrode S.E., Yager J., Heller J. \& Miller R. 2011. Proposal of a 2-tier histologic grading system for canine cutaneous mast cell tumors to more accurately predict biological behavior. Vet. Pathol. Online, New York, 48(1):147-155. <PMid:21062911>

Kummel B.A. 1996. Dermatologia de Pequenos Animais. Manole, São Paulo. $1130 \mathrm{p}$.

London C.A. 2010. Mast cell cancer, p.483-490. In: Weiss D.J. \& Wardrop K.J. (Eds), Schalm's Veterinary Hematology. 6th ed. Blackwell Publishing, Iowa.

London C.A. \& Seguin B. 2003. Mast cell tumors in the dog. Vet. Clin. N. Am., Small. Anim. Pract. 33(3):473-489.

London C.A., Galli S.J., Yuuki T., Hu Z.Q., Helfand S.C. \& Geissler E.N. 1999. Spontaneous canine mast cell tumors express tandem duplications in the proto-oncogene c-kit. Exp Hematol. 27(4):689-697. <http://dx.doi. org/10.1016/S0301-472X(98)00075-7> <PMid:10210327>

Lopes Y.M. 2014. Modalidades Terapêuticas Empregadas no Tratamento do Mastocitoma Cutâneo Canino. Universidade Federal do Rio Grande do Sul, Porto Alegre. 34p.

Macy D.W. 1985. Canine mast cells tumors. Vet. Clin. N. Am., Small Anim. Pract. 15(4):783-803. <http://dx.doi.org/10.1016/S0195-5616(85)50036-4>

Madewell B.R. \& Theilen G.H. 1987. Mast cell and melanocytic neoplasms, p.310-317. In: Theilen G.H. (Ed.), Veterinary Cancer Medicine. Lea and Febiger, Philadelphia.

Miller R.L., Van Lelyveld S., Warland J., Dobson J.M. \& Foale R.D. 2014. A retrospective review of treatment and response of high-risk mast cell tumours in dogs. Vet. Comp. Oncol. 14(4):361-370. <http://dx.doi. org/10.1111/vco.12116><PMid:25223579>

Mullins M.N., Dernell W.S., Withrow S.J., Ehrhart E.J., Thamm D.H. \& Lana S.E. 2006. Evaluation of prognostic factors associated with outcome in dogs with multiple cutaneous mast cell tumours treated with surgery with and without adjuvant treatment: 54 cases (1998-2004). J. Am. Vet. Med. Assoc. 228(1):91-95. <http://dx.doi.org/10.2460/javma.228.1.91> <PMid:16426175>

Navega P.R.S. 2011. Mastocitomas em canídeos: estudo retrospectivo. Dissertação de Mestrado, Lisboa, Universidade Técnica de Lisboa. 119p.

Ogilvie G.K. \& Moore A.S. 1995. Mast cell tumors in dogs, p.493-510. In: Ibid. (Eds), Managing the Veterinary Cancer Patient: a practice manual. Learning Systems Company, Trenton.

Patnaik A.K., Ehler W.J. \& Macewen E.G. 1984. Canine cutaneous mast cell tumour: morphologic grading and survival time in 83 dogs. Vet. Pathol. 21(5):469-474. <http://dx.doi.org/10.1177/030098588402100503> $<$ PMid:6435301>

Rocha T.M., Farias M.R., Wouk A.F.P.F., Círio S.M. \& Miara L.C. 2004. Mastocitoma em cães: revisão. Clín. Vet. 52:42-54

Rogers K.S. 1996. Mast cell tumors: dilemmas of diagnosis and treatment. Vet. Clin. N. Am., Small Anim. Pract. 26(1):87-102. <http://dx.doi.org/10.1016/ S0195-5616(96)50008-2><PMid:8825568>

Scott D.W., Miller Junior W.H. \& Griffin C.E. 1996. Neoplastic and nonneoplastic tumors, p.1236-1414. In: Ibid. (Eds), Muller and Kirk's Small Animal Dermatology. 6th ed. Elsevier Health Sciences, USA.

Simões J.P.C., Schoning P. \& Butine M. 1994. Prognosis of canine mast cell tumors: a comparison of three methods. Vet. Pathol. 31(6):637-647. <http://dx.doi.org/10.1177/030098589403100602><PMid:7863578>

Stannard A.A. \& Pulley L.T. 1990. Tumors of the skin and soft tissues, p.2387. In: Moulton J.E. (Ed.), Tumors in Domestic Animals. 3rd ed. University of California, Berkeley. 
Thamm D. \& Vail D. 2007. Mast cell tumors, p.402-424 In: Withrow S.J. \& Vail D.M. (Eds), Small Animal Clinical Oncology. 4th ed. Saunders Elsevier, St Louis. <http://dx.doi.org/10.1016/B978-072160558-6.50022-8>.

Thamm D.H., Mauldin E.A. \& Vail D.M. 1999. Prednisone and vinblastine chemotherapy for canine mast cell tumor: 41 cases (1992-1997). J. Vet. Intern. Med. 13(5):491-497. <PMid:10499735>

Thamm D.H., Turek M. \& Vail D.M. 2006. Outcome and prognostic factors following adjuvant prednisone/vinblastine chemotherapy for high-risk canine mast cell tumour: 61 cases. J. Vet. Med. Sci. 68(6):581-587.<http:// dx.doi.org/10.1292/jvms.68.581> <PMid:16820715>
Vail D.M. 1996. Mast cell tumors, p.192-210. In: Withrow S.J. \& Macewen E.G. (Eds), Small Animal Clinical Oncology. 2nd ed. W.B. Saunders, Philadelphia.

Warland J. \& Dobson J. 2013. Breed predispositions in canine mast cell tumour: a single centre experience in the United Kingdom. Vet. J. 197(2):496-498 <http://dx.doi.org/10.1016/j.tvjl.2013.02.017><PMid:23583004>

Welle M.M., Bley C.R., Howard J. \& Rüfenacht S. 2008. Canine mast cell tumours: a review of the pathogenesis, clinical features, pathology and treatment. Vet Dermatol. 19(6):321-339. <http://dx.doi.org/10.1111/j.1365-3164.2008.00694 $\mathrm{x}><$ PMid:18980632> 